\title{
A OBMEP COMO FERRAMENTA METODOLÓGICA
}

\author{
Riane Leitão Bezerra ${ }^{1}$ \\ Francisco Jucivânio Félix de Sousa ${ }^{2}$ \\ Jarles Lopes de Medeiros ${ }^{3}$
}

\begin{abstract}
Resumo: $\mathrm{O}$ presente trabalho tem como objeto de estudo as metodologias utilizadas pelos professores na preparação dos alunos para OBMEP e como essas podem influenciar nos processos de ensino e aprendizagem em uma escola do município de Crateús. Nessa perspectiva, foi realizada uma pesquisa bibliográfica, com o intuito de descrever as principais características da OBMEP. O estudo se ancora nos pesquisadores Lima e Ramos (2016), Maranhão (2010), Biondi, Vasconcelos e Menezes-Filho (2012). Realizou-se, também, uma pesquisa de campo, de cunho qualitativo, com os professores de uma escola da rede estadual de Crateús, na qual se verificou um aumento significativo no número de premiaçôes nas últimas ediçóes da olimpíada, fato que justificou a escolha da instituição nesta pesquisa. Para a coleta de dados, realizou-se uma entrevista semiestruturada. Ficou evidente que a metodologia da resoluçáo de problemas, utilizada pelos professores na preparação dos alunos para a OBMEP, tem alcançado bons resultados, tanto na olimpíada como na melhoria no aprendizado dos alunos nas aulas de Matemática. O estudo da temática possibilitou concluir que o uso didático da resolução de problemas no trabalho pedagógico da OBMEP é uma ferramenta metodológica eficaz, pois desenvolve nos alunos habilidades específicas, tais como raciocínio, argumentação e modelagem, que os possibilitam ter uma aprendizagem significativa e, consequentemente, uma melhoria na qualidade do ensino de Matemática.
\end{abstract}

Palavras-chave: OBMEP. Resolução de Problemas. Professor.

1 Graduação em Licenciatura em Matemática pelo Instituto Federal de Educação, Ciência e Tecnologia do Ceará - Campus Crateús; Especialização em Ensino de Ciências da Natureza e Matemática pelo Instituto Federal de Educação, Ciência e Tecnologia do Ceará - Campus Crateus. Contato: riane.leitao39@gmail.com

2 Doutorando do Programa de Pós-Graduação Stricto Sensu em Ensino - PPGEnsino da Universidade do Vale do Taquari - Univates. Professor de Matemática do Instituto Federal de Educação, Ciência e Tecnologia do Ceará - IFCE/ Campus- Maracanaú. E-mail: jucivanio.felix@ ifce.edu.br

3 Doutorando e Mestre em Educação pelo Programa de Pós-Graduação em Educação Brasileira da Universidade Federal do Ceará (PPGE/UFC). Licenciado em Pedagogia pela Universidade Estadual do Ceará (UECE) e licenciado em Língua Portuguesa pela Faculdade da Grande Fortaleza (FGF). Especialista em Psicopedagogia Institucional e Clínica pela Faculdade da Aldeia de Carapicuíba (FALC). Professor do Curso de Pedagogia da UECE e professor de Língua Portuguesa na Secretaria da Educação do Ceará (SEDUC). E-mail: jarlelope@gmail.com 


\title{
OBMEP AS A METHODOLOGICAL TOOL
}

\begin{abstract}
The present work has as object of study the methodologies used by teachers in preparing students for OBMEP and how they can influence the teaching and learning processes in a school in the municipality of Crateús. In this perspective, a bibliographic research was carried out, in order to describe the main characteristics of OBMEP. The study is anchored by researchers Lima and Ramos (2016), Maranhão (2010), Biondi, Vasconcelos and Menezes-Filho (2012). A qualitative field research was also carried out with the teachers of a school in the Crateús city, in which there was a significant increase in the number of awards in the last editions of the Olympics, a fact that justified the choice of institution in this research. For data collection, we conducted a semi-structured interview. It was evident that the problem solving methodology, used by teachers in preparing students for OBMEP, has achieved good results, both in the Olympics and in improving students' learning in Mathematics classes. The study of the theme enabled us to conclude that the didactic use of problem solving in the pedagogical work of OBMEP is an effective methodological tool, as it develops specific skills in students, such as reasoning, argumentation and modeling, which enable them to have meaningful learning and, consequently, an improvement in the quality of mathematics teaching.
\end{abstract}

Keywords: OBMEP. Problem solving. Teacher.

\section{Introduçáo}

Atualmente, grande parte dos alunos possui uma visão distorcida do que vem a ser o ensino e a aprendizagem dos conceitos de Matemática. Sousa et al. (2014) afirmam que é importante o uso de recursos que tornem o ensino e a aprendizagem de Matemática mais significativos e atrativos para os mesmos. Assim, aulas tradicionais da disciplina, que utilizam apenas memorizaçóes de fórmulas e reprodução das mesmas, não são interessantes para o aluno, pois é preciso que os conteúdos sejam trabalhados de forma contextualizada e com os objetivos definidos (SOUSA et al., 2014).

Além disso, constatou-se o baixo rendimento em Matemática dos estudantes brasileiros no Programa Internacional de Avaliação de Estudantes (Pisa) ${ }^{4}$ dos últimos anos, no qual as notas na disciplina vêm diminuindo a cada edição. Na última avalição do Pisa, em 2015, o Brasil ocupou a 66ª posição em Matemática, tendo como média 401 pontos, distanciando-se do primeiro colocado por uma diferença de 155 pontos.

4 O Programme for International Student Assessment (Pisa) - Programa Internacional de Avaliação de Estudantes - é uma iniciativa de avaliaçáo comparada, aplicada de forma amostral a estudantes matriculados a partir do $7^{\circ}$ ano do ensino fundamental, na faixa etária de 15 anos, idade em que se pressupóe o término da escolaridade básica obrigatória na maioria dos países. Disponível em: http://portal.inep.gov.br/web/guest/pisa. Acesso em: 10 fev. 2020. 
Os baixos índices educacionais referentes à disciplina em questão podem ser observados nos dados do Índice de Desenvolvimento da Educação Básica (Ideb) ${ }^{5}$ de 2017, o qual é calculado com base no aprendizado dos alunos em Português e Matemática (Prova Brasil) e no fluxo escolar (taxa de aprovação). O país tinha como meta para o ensino médio da rede pública alcançar nota 4,4, mas obteve, apenas, a nota 3,5 .

Em razão desses baixos rendimentos, e em busca de novas formas de inovação nas aulas de Matemática, têm-se opçóes de recursos metodológicos que podem ser utilizados como forma de elevar esses índices. Exemplos dessas inovações, conforme Andrade (2020), são: a modelagem matemática, a etnomatemática, a resolução de problemas, desafios e jogos on-line, o trabalho com materiais alternativos, dentre outros.

$\mathrm{Na}$ presente pesquisa será explanado acerca da Olimpíada Brasileira de Matemática das Escolas Públicas (OBMEP), criada em 2005, buscando compreender como ela vem sendo utilizada por alguns professores dessa disciplina, como recurso para melhorar a aprendizagem do ensino de Matemática, e propor, ao final, a utilização do uso de resolução de problemas nas aulas.

A OBMEP é um projeto nacional dirigido às escolas das redes públicas e privadas brasileiras com o intuito de estimular o estudo da Matemática, além de ofertar premiaçóes e oportunidade em programas conceituados. Nas pesquisas realizadas no site oficial da $\mathrm{OBMEP}^{6}$, verificou-se que, nas três últimas ediçôes, o estado do Ceará conquistou quase $6 \%$ de todas as premiaçóes distribuídas pelo país em cada edição. Desses resultados, vale destacar o crescimento do número de premiaçóes adquiridas pela cidade de Crateús, que no ano de 2015 obteve $0,54 \%$, em 2016 conseguiu 0,68\% e em 2017 logrou 1,01\% do total alcançado pelo estado.

Dessa forma, diante dos resultados apresentados por uma escola pública do município de Crateús nas últimas edições da OBMEP, surgiu o seguinte questionamento: que metodologias os professores dessa escola utilizam para o aumento acentuado na obtenção de prêmios em algumas ediçóes da Olimpíada e como essas poderiam influenciar no aprendizado dos alunos na disciplina de Matemática?

Dessa forma, apresenta-se como objetivos específicos: descrever como se configura a OBMEP; investigar fatores que influenciam para o alcance dos resultados apresentados na OBMEP; discutir a percepção dos professores de Matemática sobre as melhorias nos processos de ensino e aprendizagem nas aulas da disciplina.

5 O Ideb foi criado em 2007, e reúne, em um só indicador, os resultados de dois conceitos igualmente importantes para a qualidade da educação: o fluxo escolar e as médias de desempenho nas avaliaçóes. Ele é calculado a partir dos dados sobre aprovaçáo escolar, obtidos no Censo Escolar, e das médias de desempenho nas avaliaçóes do Inep, o Saeb, para as unidades da federação e para o país, e a Prova Brasil, para os municípios. Disponível em: http://portal.inep.gov.br/web/ guest/ideb. Acesso em: 10 fev. 2020.

6 Disponível em: http://www.obmep.org.br/. Acesso em: 20 nov. 2020. 
A escolha do tema se justifica pelo aumento no número de premiaçóes conquistadas pela Escola do Planalto ${ }^{7}$, tomando como exemplo as ediçóes da Olimpíada dos anos 2016 e 2017, em que a escola obteve 25\% das premiaçóes do nível 3 e 86,36\% das premiaçóes, respectivamente, na cidade de Crateús. Ainda se pode destacar a edição de 2018: dentre as 25 premiaçóes que a cidade conseguiu, 16 foram para a escola pesquisada. Justifica-se, também, pela importância de tais metodologias para o aprendizado dos alunos em Matemática, e, em consequência, a melhoria dos resultados obtidos.

Todavia, para o estudo crítico do tema, utilizou-se como fundamentaçáo teórica as pesquisas realizadas pelos seguintes autores: Diogo (2016), nas quais realiza um estudo sobre as práticas docentes que propiciam um ensino de qualidade, tendo como foco a OBMEP; Lima e Ramos (2016), os quais analisam as implicaçóes da OBMEP nos processos de ensino e aprendizagem de Matemática nas escolas públicas de Água Branca e Estado do Piauí, sob a ótica dos docentes; e por Maranhão (2010), que avalia o impacto da olimpíada na comunidade escolar e na comunidade externa a partir das percepçóes dos alunos, professores, pais de alunos, gestores educacionais e do público em geral, destacando os pontos positivos negativos e as sugestôes para o aprimoramento, entre outros. Assim, esses pesquisadores possibilitam uma melhor compreensão acerca da problemática sob diversas perspectivas em torno do tema.

Como método, realizou-se uma análise documental dos dados contidos no site oficial da OBMEP ${ }^{8}$, o que possibilitará entender como se organiza a olimpíada, e coletar dados sobre as premiaçóes conquistadas pela escola pesquisada. Além de ter sido realizada uma pesquisa in loco (na escola), entrevistou-se os professores de Matemática da instituiçáo para analisar as metodologias utilizadas pelos mesmos, as quais podem ter motivado o bom desempenho nas últimas ediçóes da OBMEP (hipótese inicial deste estudo), e, assim, verificou-se também a percepção dos mesmos sobre os processos de ensino e aprendizagem dos alunos nas aulas da disciplina

Compreende-se que a pesquisa nessa temática se torna importante para o estudo dessas metodologias de sucesso utilizadas pelos professores da escola na obtenção de bons resultados na OBMEP, uma vez que as mesmas, além de proporcionarem incentivo ao estudo da Matemática, podem oportunizar melhorias nos processos de ensino e aprendizagem dos alunos no decorrer da disciplina. Assim, esta investigação servirá de base para outras escolas da região, como embasamento para implantaçáo de projetos que visem o sucesso de seus alunos na disciplina e, consequentemente, bons resultados na olimpíada.

7 Nome fictício que será utilizado para a descrição escola estudada durante a pesquisa realizada.

8 Disponível em: http://www.obmep.org.br/. Acesso em: 10 fev. 2020. 


\section{A OBMEP e o ensino de Matemática}

Nesta seção, será detalhada a configuração da OBMEP, destacando seus pontos relevantes. Também seráo apresentados alguns estudos que têm a olimpíada como finalidade e, na sequência, será discorrido sobre essa como ferramenta metodológica.

OBMEP teve sua primeira edição no ano de 2005. Foi criada com o intuito de incentivar o estudo da Matemática nos alunos da rede pública de ensino e descobrir talentos na área. Inicialmente, era voltada exclusivamente para as escolas públicas e, a partir do ano de 2017, a olimpíada também foi direcionada às escolas particulares. Trata-se de um projeto nacional que foi inspirado no Projeto Numetizar ${ }^{9}$, desenvolvido no ano de 2003, no estado do Ceará, cujo objetivo principal era a melhoria da educação pública, visando à generalização dos bons resultados encontrados com o projeto.

A OBMEP é realizada pelo Instituto Nacional de Matemática Pura e Aplicada (IMPA), tendo como arrimo a Sociedade Brasileira de Matemática (SBM), e produzida com recursos do Ministério da Educação (MEC) e do Ministério da Ciência, Tecnologia, Inovaçóes e Comunicaçóes (MCTIC) (OBMEP, 2018).

A OBMEP tem como objetivos centrais:

- Estimular e promover o estudo da Matemática;

- Contribuir para a melhoria da qualidade da educação básica, possibilitando que um maior número de alunos brasileiros possa ter acesso a material didático de qualidade;

- Identificar jovens talentos e incentivar seu ingresso em universidades, nas áreas científicas e tecnológicas;

- Incentivar o aperfeiçoamento dos professores das escolas públicas, contribuindo para a sua valorização profissional;

- Contribuir para a integração das escolas brasileiras com as universidades públicas, os institutos de pesquisa e com as sociedades científicas;

- Promover a inclusão social por meio da difusão do conhecimento (OBMEP, 2018).

Vale ressaltar que um dos objetivos da OBMEP é a melhoria da qualidade do ensino, para a qual essa disponibiliza material de apoio, como banco de questóes com soluçóes que ajudam no estudo da disciplina. A olimpíada também oferece alguns programas, dentre os quais o Portal da Matemática, que disponibiliza videoaulas e lista de exercícios, com conteúdos de Matemática que abrangem o currículo escolar do $6^{\circ}$ ano do ensino fundamental ao $3^{\circ}$ ano do ensino médio, contribuindo com uma quantidade maior de materiais disponíveis para serem usados pelos professores em sala de aula.

9 Em 2003 o governo do estado do Ceará criou o Projeto Linguagem das Letras e dos Números - Numeratizar e Leituralizar, devido à experiência do estado no que concerne às olimpíadas de Matemática. Disponível em: http://sbpcnet.org.br/livro/57ra/programas/CONF_SIMP/textos/ joaolucasbarbosa-simp.htm. Acesso em: 20 fev. 2020. 
A OBMEP é composta por duas fases: a primeira consiste em uma prova de múltipla escolha e a segunda em uma prova discursiva, a qual é destinada para apenas $5 \%$ dos inscritos de cada nível. É distribuída em três níveis, organizados de acordo com a escolaridade em três grupos de acordo o nível de escolaridade: "Nível 1: $5^{\mathrm{a}}$ série/ $6^{\mathrm{o}}$ ano e $6^{\mathrm{a}}$ série/7o ano do Ensino Fundamental. Nível 2: $7^{\mathrm{a}}$ série $/ 8^{\circ}$ ano e $8^{a}$ série/9o ano e Nível 3: Ensino Médio (OBMEP, 2018).

A olimpíada contou com mais de 10 milhóes de participantes brasileiros em sua primeira edição, ocorrendo um aumento de quase $35 \%$ na edição seguinte, e constante aumento em ediçôes posteriores. A tabela 1, a seguir, mostra o total de inscritos na primeira fase da olimpíada em todo o Brasil:

Tabela 1 - Inscritos na1 a fase $(2005$ - 2017)

\begin{tabular}{c|c|c|c}
\hline \multicolumn{5}{|c}{ OBMEP 1 ${ }^{\mathrm{a}}$ FASE } \\
\hline ANO & ESCOLAS & ALUNOS & MUNICÍPIOS \\
\hline 2005 & 31.655 & 10.520 .831 & $93,50 \%$ \\
\hline 2006 & 32.655 & 14.181 .705 & $94,50 \%$ \\
\hline 2007 & 38.450 & 17.341 .732 & $98,10 \%$ \\
\hline 2009 & 40.397 & 18.326 .029 & $98,70 \%$ \\
\hline 2010 & 43.854 & 19.198 .710 & $99,10 \%$ \\
\hline 2011 & 44.717 & 19.665 .928 & $99,16 \%$ \\
\hline 2012 & 44.691 & 18.720 .068 & $98,90 \%$ \\
\hline 2013 & 46.728 & 19.166 .371 & $99,42 \%$ \\
\hline 2014 & 47.144 & 18.762 .859 & $99,35 \%$ \\
\hline 2016 & 46.711 & 18.192 .526 & $99,41 \%$ \\
\hline 2017 & 47.580 & 17.972 .333 & $99,48 \%$ \\
\hline
\end{tabular}

Fonte: Elaborado pelos autores com base nos dados disponíveis no site da OBMEP $^{10}$.

Apesar de apenas 5\% dos alunos com melhor rendimento na primeira fase em cada nível serem classificados para a segunda fase, pode-se perceber na tabela 2 um aumento de $72,55 \%$ na participação dos discentes da primeira para a segunda edição. A participação dos estudantes na segunda fase continua crescendo nas ediçóes seguintes, o que também pode ser analisado na tabela 2 .

10 Disponível em: http://www.obmep.org.br/. Acesso em: 10 fev. 2020. 
Tabela 2 - Alunos classificados para $2^{\text {a }}$ fase $(2005-2017)$

\begin{tabular}{c|c|c|c}
\hline \multicolumn{3}{c}{ OBMEP 2a FASE } \\
\hline ANO & ESCOLAS & ALUNOS & MUNICÍPIOS \\
\hline 2005 & 29.074 & 457.725 & $91,90 \%$ \\
\hline 2006 & 29.661 & 630.864 & $92,40 \%$ \\
\hline 2007 & 35.483 & 780.333 & $96,90 \%$ \\
\hline 2008 & 35.913 & 789.998 & $96,90 \%$ \\
\hline 2009 & 39.387 & 841.139 & $98,10 \%$ \\
\hline 2010 & 39.929 & 863.000 & $98,30 \%$ \\
\hline 2011 & 39.935 & 818.566 & $98,10 \%$ \\
\hline 2012 & 40.770 & 823.871 & $98,50 \%$ \\
\hline 2013 & 42.480 & 954.926 & $98,83 \%$ \\
\hline 2014 & 41.302 & 907.446 & $99,41 \%$ \\
\hline 2015 & 42.316 & 889.018 & $97,62 \%$ \\
\hline 2016 & 43.232 & 913.889 & $99,05 \%$ \\
\hline 2017 & 49.617 & 941.630 & $99,23 \%$ \\
\hline
\end{tabular}

Fonte: Elaborado pela autora com base nos dados disponíveis no site da OBMEP.

A partir dos dados expostos acima (tabelas 1 e 2), compreende-se que, além do número de inscritos, o número de escolas participantes aumentou no decorrer dos anos: passou de 31.655, no ano de 2005, para 53.231, no ano de 2017, na $1^{\text {a }}$ fase da olímpiada; e de 29.074, em 2005, para 49.617, em 2017, na segunda fase. A quantidade de municípios que aderiram à OBMEP também cresceu desde a primeira edição, aumentando de 93,50\%, em 2005, para 99,57\%, em 2017 ( $1^{\text {a }}$ fase). A porcentagem dos municípios brasileiros que participaram da $2^{\text {a }}$ fase é equivalente a que participou da $1^{\text {a }}$ fase, embora o número de alunos e escolha tenha diminuído.

\section{Pesquisas que trazem a OBMEP como objeto de estudo}

A OBMEP, nos últimos anos, tem ganhado atençáo especial por parte de autores que estudam a educação matemática, fazendo com que surjam novos caminhos, possibilitando outros que pesquisadores apresentarem trabalhos com esse tema. Aqui, destacar-se-á algumas dessas pesquisas que trazem a olimpíada como seu campo principal de estudo.

Os autores Lima e Ramos (2016) fazem uma análise da OBMEP sob a percepção dos docentes das escolas públicas de Água Branca -PI. Têm como objetivo analisar as implicaçóes da olimpíada nos processos de ensino e aprendizagem de Matemática na cidade, no período entre 2005 e 2014. Nessa perspectiva, os autores realizaram uma pesquisa de campo com enfoque qualitativo com 10 profissionais 
de 05 escolas participantes da OBMEP, os quais foram submetidos a entrevista gravada, com o uso de questionário semiestruturado.

A partir do estudo dessa temática, Lima e Ramos (2016) afirmam que a OBMEP não tem se tornado só uma olimpíada que abrange diversos alunos, escolas e municípios. Trata-se de uma política pública educacional "[...] que tem contribuído para mudanças nas estratégias de ensino de matemática nas escolas públicas brasileiras, na medida em que se utiliza da resolução de problemas como estratégia de avaliação dos conhecimentos em matemática" (LIMA; RAMOS 2016, p. 10).

Em contradição a esse pensamento, Cocco (apud LIMA; RAMOS, 2016) aponta a prova da OBMEP como um aspecto negativo, que ao invés de estimular a motivação para o estudo da disciplina, a olimpíada, como um sistema de prova competitivo, tem por consequência a exclusão na seleção desses alunos, ocasionando o contrário do que propóem os objetivos da mesma.

Lima e Ramos (2016) apontam, ainda, que, segundo os professores entrevistados, certamente, a participaçáo das escolas nesse processo pode estar correlacionada com a importância atribuída a esse evento, pois quando perguntados "qual a importância que a OBMEP tem para a escola?", é possível perceber respostas que apontam para a olimpíada como importante para o desenvolvimento cognitivo dos alunos e instrumento de metodologia de ensino e avaliaçáo, e também a conquista de uma medalha, segundo os docentes pesquisados, incentiva o aluno a conquistar melhores resultados. Logo, nota-se, de acordo com os professores que contribuíram para a pesquisa dos autores, a olimpíada como sendo um fator estimulante na possível escolha da profissáo do aluno, indo de encontro com a ideia do autor Cocco, no parágrafo anterior.

Dessa forma, pode-se perceber com os estudos realizados por Lima e Ramos (2016) que, além do aumento no número de adeptos, a olimpíada pode ser usada nas aulas de Matemática como estratégia metodológica de enriquecimento das aulas, trazendo mais significado para as mesmas, possibilitando aos alunos desenvolver novas habilidades, melhorando, em consequência, a aprendizagem.

A pesquisadora Maranhão (2010) tem gerado impactos positivos tanto em relação à motivação e interesse quanto na melhoria do aprendizado dos alunos. Esse fato tem contribuído para a consolidação OBMEP como "[...] uma política pública mundialmente reconhecida, uma das maiores iniciativas governamentais voltadas ao processo de ensino-aprendizagem em matemática, visando melhorar a motivaçáo, o interesse e o desempenho dos alunos nas escolas públicas brasileiras" (MARANHÃO, 2010, p. 13).

Biondi, Vasconcelos e Menezes-Filho (2012) também relatam aspectos positivos da OBMEP, pois destacam que escolas que participam de forma contínua 
da olimpíada tem um aumento de quase 2 pontos na nota média da Prova Brasil ${ }^{11}$. Ainda, segundo os autores, há um crescimento "[...] de 2,28 pontos na nota média de Matemática em escolas que participaram três vezes da Olimpíada, e 1,30 para escolas que participaram duas vezes" (BIONDI; VASCONCELOS; MENEZESFILHO, 2012, p. 3).

Moreira (2017) apresenta, como resultado da sua pesquisa, que a OBMEP traz benefícios tanto para os alunos premiados quanto para os seus colegas de turma, constatando que o rendimento de ambos cresceu significativamente. Outro fato que merece destaque, ainda segundo a autora, é que, ao continuar observando o percurso desses alunos até o ingresso na educaçáo superior, percebeu que a probabilidade de um aluno premiado ingressar em um curso superior mais concorrido era $17 \%$ maior em relação ao aluno de igual desempenho não premiado. Já para os colegas de turma, essa probabilidade aumentou em 10\%, na comparação com os alunos da outra classe, onde não havia premiados.

Portanto, a partir desses pensamentos, pode-se perceber que esses autores mostram o quão valiosa é a OBMEP para os processos de ensino e aprendizagem de Matemática, pois possibilita uma melhoria na qualidade do ensino, aumenta a motivação, desperta o interesse e, como consequência, tem uma melhoria no rendimento dos alunos na disciplina.

\section{A OBMEP como ferramenta metodológica}

O desempenho dos alunos do ensino básico na disciplina de Matemática vem caindo, conforme Dantas Filho (2017), uma vez que muitos não veem motivação para se dedicar, não encontram significado nas aulas, as quais continuam tradicionais, a disciplina é tida como um "bicho papão". Devido a esses e outros fatores, os resultados obtidos nas avaliaçóes externas não estão apresentando crescimento.

À vista disso, pode-se compreender que, através dos índices apresentados pelas avaliaçóes externas do país, como Pisa (2015) e Ideb (2017), a nota de Matemática não apresenta crescimento e, muitas vezes, mostra um decréscimo. Assim, faz-se necessário repensar as metodologias utilizadas no ensino de Matemática, pois apenas aulas tradicionais não conseguem garantir um bom aprendizado. Dessa maneira, segundo Diogo (2016), o aluno, além de entender os princípios matemáticos, tem que saber aplicar os conteúdos estudados no seu cotidiano.

Assim, conforme indica a Base Nacional Comum Curricular (BNCC), homologada em dezembro de 2018:

[...] os estudantes devem desenvolver habilidades relativas aos processos de investigação, de construção de modelos e de resolução de problemas. Para

11 A Prova Brasil é uma avaliação para diagnóstico, em larga escala, e tem o objetivo de avaliar a qualidade do ensino oferecido pelo sistema educacional brasileiro a partir de testes padronizados e questionários socioeconômicos. Disponível em: http://portal.mec.gov.br/prova-brasil. Acesso em: 10 fev. 2020. 
tanto, eles devem mobilizar seu modo próprio de raciocinar, representar, comunicar, argumentar e, com base em discussóes e validaçóes conjuntas, aprender conceitos e desenvolver representaçóes e procedimentos cada vez mais sofisticados" (BRASIL, 2017, p. 529).

Percebe-se que o método da resolução de problemas é um recurso valioso no processo de ensino e aprendizagem de Matemática, uma vez que proporciona o processo de aprendizado com mais significado, desenvolvendo habilidades como raciocinar, argumentar, desenvolver estratégias, dentre outras.

Um dos intuitos da OBMEP é estimular o estudo da Matemática, por isso são disponibilizados materiais no site oficial que ajudam nesse processo, além dos programas oferecidos para promoção desse estudo. A disponibilização desses materiais e a criação desses programas buscam desenvolver as habilidades que estão descritas na BNCC (BRASIL, 2017), como destacado anteriormente, visando desenvolver no aluno capacidades como raciocinar, argumentar, modelar problemas, indo ao encontro com o que a BNCC, afirma e com o propósito do método da resolução de problemas.

Destacando ainda os programas oferecidos pela OBMEP, salienta-se, como exemplo desses programas, o Programa OBMEP na Escola, que é voltado para os professores de Matemática das escolas públicas e para os alunos de licenciatura em Matemática, tendo como objetivo contribuir para a formação de professores da referida disciplina, estimulando estudos mais aprofundados e a adoção de novas práticas didáticas em suas salas de aula. Esse programa orienta os professores no desenvolvimento de conteúdos programáticos, usando a resolução de problemas como ferramenta metodológica para trabalharem com grupos de alunos selecionados em suas escolas ou em escolas vizinhas.

Dessa forma, a OBMEP pode ser usada como um procedimento metodológico, baseado na resolução de problemas, nas aulas de Matemática, além de fornecer ao aluno problemas desafiadores, que segundo Polya (apud DIOGO, 2016, p. 9):

Uma grande descoberta resolve um grande problema, mas há sempre uma pitada de descoberta na resoluçáo de um problema. O problema pode ser modesto, mas se ele desafiar a curiosidade e puser em jogo as faculdades inventivas, quem o resolver pelos próprios meios, experimentar à tensão e gozará o triunfo da descoberta. Experiências tais, numa idade susceptível, poderão gerar o gosto pelo trabalho mental e deixar, por toda a vida, a sua marca na mente e no caráter.

Vale destacar que as questôes propostas pelo professor na metodologia de resolução de problemas devem instigar no educando à curiosidade, devem desafiá-lo a encontrar a solução usando seus próprios métodos, fazendo com que tenha uma aprendizagem significativa, a qual, segundo Ausubel (apud MOREIRA, 2011), caracteriza-se pela relação entre os conhecimentos prévios e os novos conhecimentos que os alunos adquirem, ou seja, as experiências que os discentes levam para a sala de aula são consideradas durante os processos de ensino e aprendizagem. 


\section{Metodologia}

A escolha do tema se deu após se ter assistido a uma entrevista ${ }^{12} \mathrm{em}$ janeiro de 2018, com o diretor do IMPA, Marcelo Viana, na qual esse destacou a importância da OBMEP para os processos de ensino e aprendizagem da Matemática nas escolas participantes. A partir de tal afirmação, surgiu a curiosidade de investigar se alguma escola de Crateús realizava um trabalho voltado para a OBMEP, e como esse poderia influenciar no aprendizado da disciplina.

Dessa forma, ao realizou-se uma pesquisa no site oficial da olimpíada, a partir da qual se observou um crescente aumento nas premiaçóes obtidas por uma escola da cidade. Assim, optou-se por realizar uma pesquisa descritiva, de cunho qualitativo, na referida instituiçáo, visando pesquisar as metodologias utilizadas pelos professores da disciplina que levam ao sucesso a participação da escola na OBMEP.

À vista disso, a pesquisa realizada, neste trabalho, é de natureza predominantemente qualitativa, pois essa abordagem, segundo Appolinário (2012), faz uma coleta de dados a partir de diálogos sociais com o objeto de estudo, possibilitando, assim, discussões sobre a percepção dos professores de Matemática em relação ao efeito da olimpíada nas aulas da disciplina.

Trata-se de um estudo descritivo, pois, primeiramente, apresenta-se como se configura a OBMEP no seu contexto histórico, levantando alguns dados importantes para o trabalho. Também se observou a forma como a olimpíada é utilizada como ferramenta metodológica no processo de ensino de Matemática. Como instrumento de coleta de dados, realizou-se uma entrevista semiestruturada, contendo as questóes a seguir:

- Quando o trabalho voltado para a OBMEP começou a ser desenvolvido?

- Quais as metodologias que você utiliza na preparaçáo dos alunos para a olimpíada?

- Como se deu a motivação para esse tipo de trabalho?

- Os professores envolvidos recebem ou receberam algum tipo de formação para trabalhar nessa área?

- Quais as melhorias no processo de aprendizagem em Matemática dos seus alunos?

- Os alunos que participam da formação melhoram na disciplina de Matemática?

- De que forma a OBMEP afetou o seu trabalho?

- Você vê algo a ser melhorado nesse trabalho voltado para a OBMEP?

12 Entrevista realizada no dia 13 de novembro de 2017, apresentada no programa "Conversa com Bial", da Rede Globo. Disponível em: https://impa.br/page-noticias/conversa-com-bialentrevista-diretor-e-pesquisadora-do-impa/. Acesso em: 10 fev. 2020. 
- O quanto você se sente apoiado pelo IMPA? Você tem alguma sugestáo de como eles poderiam melhorar o apoio que eles fornecem aos professores que trabalham nessa área?

- Você pretende continuar trabalhando com formação voltada para as olimpíadas?

Inicialmente, a entrevista seria realizada com os quatro professores de Matemática da Escola do Planalto, e apesar de o contato ter sido realizado com todos, apenas dois retornaram uma resposta. $\mathrm{Na}$ entrevista, foram abordados pontos que buscavam responder como as metodologias utilizadas por esses profissionais justificavam o crescente aumento no número de premiaçóes angariadas pela escola estudada. Com esse recurso, também se buscou analisar a concepção dos professores sobre como tais metodologias podem suscitar melhorias nos processos de ensino e aprendizagem nas aulas de Matemática durante a preparação desses alunos para a OBMEP.

\section{Resultados e discussóes}

Nesta seção, serão apresentadas as reflexóes acerca das entrevistas realizadas com os professores da Escola do Planalto, no período de dezembro de 2018. As entrevistas discorrem sobre a formação, motivação, metodologias e sobre a percepção dos professores na melhoria apresentada pelos alunos nos processos de ensino e aprendizagem nas aulas de Matemática. Os professores não foram identificados e receberam os códigos $\mathrm{P} 1$ e $\mathrm{P} 2$.

O trabalho de preparação para a OBMEP desenvolvido na escola é um projeto que teve como idealizador o $\mathrm{P} 1$. Os demais professores não trabalham diretamente nesse projeto, apenas fazem algumas contribuiçóes. O projeto acontece em forma de aulas extras, aos sábados, durante todo o ano. $\mathrm{O}$ público de abrangência é reduzido, apenas alguns alunos participam e a escolha se dá por interesse e por indicação e motivação dos professores.

Os docentes de Matemática da escola pesquisada são, em sua maioria, do sexo masculino (75\%), todos formados em Matemática, e um deles possui mestrado também na área. Apenas um dos quatro professores faz parte do quadro efetivo da Secretaria da Educação (Seduc), os demais são contratados por tempo determinado. Dos educadores que contribuíram com a pesquisa, todos já lecionam há algum tempo, um deles já tem uma vasta experiência com 15 anos.

Os professores entrevistados, quando questionados sobre quando se deu o início dos trabalhos voltados para a OBMEP, relataram que sempre houve uma preocupaçáo com o tempo na preparação dos alunos para a olimpíada, mas a intensificação se deu com a iniciativa de $\mathrm{P} 1$, pois essa já havia desenvolvido um trabalho semelhante em outra cidade onde atuou como professora, além da OBMEP ter sido o seu objeto de estudo no mestrado.

Já quando os mesmos foram questionados sobre qual a motivação de se fazer uma preparação dos alunos para a olimpíada, P2 relatou que busca despertar 
o interesse dos jovens pela Matemática, desenvolver a capacidade dos alunos de racionar e imaginar e moldar problemas para conseguir encontrar a solução deles.

Esse pensamento remete à metodologia da resolução de problemas, a partir da qual os alunos são instigados a moldarem suas próprias soluçóes, tendo, assim, uma aprendizagem significativa, em que, segundo Sousa (apud LIMA; RAMOS (2016, p. 17-18), a "[...] resoluçáo de problemas pode ser utilizada como uma estratégia didática eficaz e capaz de despertar no aluno a curiosidade, estimulando-o a buscar novas situaçôes, tornando-o capacitado e motivado". Assim, possibilita ao educando a aquisição de diversas competências. Essa concepçáo de P2 leva também a um dos objetivos da OBMEP, que é estimular o estudo de Matemática, pois se o aluno é instigado a situaçóes desafiadoras, consequentemente se motivará a buscar soluçóes e, dessa forma, desenvolverá uma atração maior pela disciplina.

Já $\mathrm{P} 1$, destaca que sua motivação surgiu desde a formação, pois sempre teve um forte apreço pela OBMEP e quis possibilitar para os alunos o contato com uma matemática mais avançada, com definições que geralmente não são ensinadas em sala de aula. $\mathrm{O}$ que pode ser evidenciado em sua fala:

Sempre tive uma paixão pela OBMEP, desde a minha formação, e sempre tive vontade de apresentar para os alunos uma matemática mais avançada. Então, quando cheguei na escola senti a necessidade de fazer um trabalho voltado para a OBMEP, pois a escola focava muito no Spaece e no Enem. A escola participava da OBMEP, mas não tinha um trabalho direcionado para ela (P1, entrevista realizada em dezembro de 2018).

Vale ressaltar, também, que P1 evidencia a importância de trabalhar a OBMEP, pois, dessa forma, além de todos os benefícios agregados aos alunos, está contribuindo diretamente para as avaliaçóes externas, como o Sistema Permanente de Avaliação da Educação Básica do Ceará (Spaece) ${ }^{13}$ e o Exame Nacional do Ensino Médio (Enem) ${ }^{14}$, o que pode ser percebido em sua fala:

O sentido de trabalhar OBMEP, é que se você trabalha OBMEP, automaticamente você está trabalhando todas as outras avaliaçóes externas, porque hoje em dia as escolas trabalham por resultados, não é como antigamente, todo mundo é cobrado por resultados, existe uma pressáo muito grande, e a forma que eu enxergo de trabalhar matemática é trabalhar com a OBMEP, porque todas as outras serão levadas juntas, se um aluno é capaz de resolver uma prova da OBMEP, ele também é capaz de resolver uma prova do SPAECE e do ENEM (P1, entrevista realizada em dezembro de 2018).

13 O Space é um sistema de avaliação em larga escala que avalia competências e habilidades na área de Língua Portuguesa e Matemática dos discentes dos ensinos fundamental e médio no estado do Ceará. Para mais informaçōes, consultar o site oficial, disponível em: http://www.spaece.caeduff. net/. Acesso em: 20 nov. 2020.

14 O Enem avalia a qualidade do ensino médio no Brasil, sendo realizado pelo Instituto Nacional de Estudos e Pesquisas Educacionais Anísio Teixeira. Para mais informações, consultar o site oficial da avaliação, disponível em: https://enem.inep.gov.br/. Acesso em: 20 nov. 2020. 
A concepçáo exposta por P1 vai ao encontro com o que dizem Biondi, Vasconcelos e Menezes-Filho (2012), que a participação contínua das escolas na OBMEP tem um aumento relevante nas avaliações externas. Isso pode ser comprovado ao se observar os resultados obtidos pela escola no Spaece no ano de 2017, avaliação em que a proficiência em Matemática foi de 309,5, superando a proficiência do estado do Ceará em 40,4 pontos.

Quando perguntados sobre quais metodologias utilizadas nas aulas de preparação para a olimpíada, todos os professores disseram que usam a resoluçáo de problemas como método de ensino. Segundo Lima e Ramos (2016, p. 15), "[...] a utilizaçáo de problemas, como metodologia de ensino, contribui para a aprendizagem do discente, uma vez que ele consegue assimilar os conteúdos matemáticos no contexto que está inserido”. Dessa forma, as aulas de Matemática têm mais significado para o aluno, influenciando diretamente no processo de ensino e aprendizagem da disciplina.

Ao serem indagados sobre quais as melhorias nos processos de ensino e aprendizagem apresentadas pelos alunos que participavam da preparação para a OBMEP, os professores responderam que há um avanço em relação ao aprendizado na disciplina, e que os mesmos repassam o conhecimento aprendido para os demais colegas, exercendo a funçáo de monitores da disciplina, como pode ser comprovado nas falas de P1 e P2:

Os alunos que participaram das aulas da OBMEP, primeiro desenvolveram uma paixáo pelo estudo da Matemática, levando essa paixão para a sala de aula regular. Dessa forma, o estudo da Matemática na escola se tornou mais forte e mais questionado. E ainda ajudaram os seus colegas de sala, com um sistema de monitoramento (P1, entrevista realizada em dezembro de 2018).

Substancialmente. Os alunos envolvidos na turma OBMEP desempenham satisfatoriamente, e acima da média, nas disciplinas como um todo, quando comparados aos alunos não diretamente envolvidos na formação (P2, entrevista realizada em dezembro de 2018).

A concepção exposta pelos docentes, descrita acima, está em concordância com Maranhão (2010), que diz que a olimpíada gera impactos positivos, pois desperta o interesse dos alunos pela disciplina, além de melhorar o aprendizado e o desempenho dos mesmos nas aulas de Matemática.

A percepção dos docentes entrevistados mostra que a metodologia da resolução de problemas traz benefícios para os alunos, possibilitando uma aprendizagem significativa e desenvolvendo neles diversas habilidades. Dessa forma, os alunos participantes da OBMEP passam a assumir posturas engajadas com os processos de ensino e aprendizagem de seus colegas, oferecendo contribuiçóes durante as aulas. Além disso, apresentam autonomia em relação a outras formas de aprender Matemática para além da sala de aula, estimulando os seus colegas nesse processo. 


\section{Algumas consideraçóes}

A discussão sobre as metodologias utilizadas pelos professores na preparação dos alunos para a OBMEP, e de como essas podem influenciar nos processos de ensino e aprendizagem dos estudantes, é de grande relevância para a educação, pois traz novas alternativas para se trabalhar com os educandos, além e oferecer suporte didático-pedagógico no trato de possíveis problemas que venham surgir no cotidiano. Pesquisas como esta oferecem um leque de possibilidades, podendo ser replicadas e também gerar casos de sucesso, como na pesquisa apresentada.

Por conseguinte, a partir do estudo desse assunto, é perceptível a existência de uma interação entre a Matemática e a OBMEP, pois, como afirma Lima e Ramos (2016), a olimpíada tem se tornado, ao longo das últimas ediçóes, bastante abrangente, podendo contribuir para a melhoria da qualidade das aulas da disciplina, inovando nas estratégias metodológicas por meio da resolução de problemas.

Dessa forma, partindo desse objetivo, verificaram-se dois pontos importantes. O primeiro faz referência à importância de usar a resoluçáo de problemas como ferramenta metodológica, uma vez que proporciona ao educando uma interação entre o conteúdo estudado e o meio em que o aluno está inserido, contribuindo, assim, para uma aprendizagem significativa para o aluno.

O segundo ponto se refere sobre a melhoria do rendimento do aluno na disciplina de Matemática, como afirma Lima e Ramos (2016), pois, ao se trabalhar a resoluçáo de problemas, usando questóes da OBMEP, instigando o aluno a resolver problemas desafiadores, como os propostos pela olimpíada, desenvolvese habilidades específicas, como a criatividade, o raciocínio, a argumentação e a modelagem, tornando o estudante capaz de progredir dentro da disciplina, ocasionando, consequentemente, uma melhoria na qualidade do ensino.

Por isso, conclui-se, com este trabalho, que se deve buscar, quando possível, metodologias que garantam uma aprendizagem significativa e, consequentemente, a melhoria nos processos de ensino e aprendizagem, e, como foi evidenciado, a OBMEP pode ser vista como uma oportunidade para que os processos de ensino e aprendizagem da Matemática possam ser compreendidos como algo que náo se limita aos espaços escolares.

Para finalizar, a partir do tema que foi desenvolvido nesta pesquisa, percebese que o professor aplica a metodologia de resolução de problemas na preparação dos alunos para a OBMEP, sendo essa metodologia um importante recurso que contribui no processo de aprendizagem dos estudantes, como foi mencionado pelos professores entrevistados. Após a utilizaçáo desse método, os alunos passaram a organizar seus pensamentos, desenvolvendo suas habilidades específicas, o que permite uma aprendizagem significativa.

Temas como esses motiva a reflexão em torno de novas linhas de pesquisa, como, por exemplo, investigar a percepção dos alunos sobre as metodologias usadas na preparaçáo para a OBMEP e como eles veem essa melhoria no rendimento da 
disciplina de Matemática. É possível, ainda, verificar se há outras metodologias que possam ter resultados satisfatórios como a resolução de problemas.

\section{Referências}

\section{ANDRADE, Simone Milagres Patrono. Etnomatemática, jogos e conteúdos} matemáticos e geométricos: um estudo com alunos do $8^{\circ}$ ano do ensino fundamental. Dissertação. 349f. Programa de Mestrado Profissional em Educação Matemática, da Universidade Federal de Ouro Preto. Ouro Preto, Minas Gerais, 2020.

APPOLINÁRIO, Fábio. Metodologia da ciência - filosofia e prática da pesquisa. São Paulo: Editora Pioneira Thomson Learning, 2012.

BIONDI, Roberta Loboda; VASCONCELLOS, Lígia; MENEZES-FILHO, Naercio. Avaliando o impacto da OBMEP - Olimpíada Brasileira de Matemática das Escolas Públicas - na qualidade da educação. Revista Economia. LACEA, v. 12, n. 2, "Spring 2012". (p.143-170). Disponível em: http://server22.obmep.org.br:8080/media/servicos/ recursos/251396.o. Acesso em: 23 mar. 2018.

BRASIL. Ministério da Educação. Base Nacional Comum Curricular (Terceira Versão). Ministério da Educação, Brasília, DF: MEC, 2017. Disponível em: http:// basenacionalcomum.mec.gov.br/images/BNCC_EI_EF_110518_versaofinal_site.pdf. Acesso em: 13 fev. 2019.

DANTAS FILHO, Jerônimo Vieira. Baixo rendimento na disciplina de matemática. EDUCA - Revista Multidisciplinar em Educação, Porto Velho, v. 4, nº 9, p. 98 a 113, set/ dez, 2017. Disponível em: https://www.periodicos.unir.br/index.php/EDUCA/article/ view/2129. Acesso em: 20 nov. 2020.

DIOGO, Janine Charlene. OBMEP - Práticas docentes que propiciam um ensino de qualidade. 2016. 37 f. TCC (Graduação) - Curso de Especialização em Matemática, Universidade do Vale do Rio dos Sinos - Unisinos, São Leopoldo, 2016. Disponível em: http://www.repositorio.jesuita.org.br/bitstream/handle/UNISINOS/5827/Janine\%20 Charlene\%20Diogo_.pdf?sequence=1\&isAllowed=y. Acesso em: 10 nov. 2018.

LIMA, Vívia Maria Rodrigues; RAMOS, Antônio Francisco. A Olimpíada Brasileira de Matemática Sob a Ótica dos Docentes das Escolas Públicas de Água Branca-PI. Somma, Teresina, v. 2, n. 1, p.6-21, jan/jun. 2016. Disponível em: https://www5.ifpi.edu.br/ revistas/index.php/somma/article/view/71. Acesso em: 14 maio 2018.

MARANHÃO, Tatiana de P. A. Avaliação de impacto da olimpíada brasileira de Matemática nas escolas públicas (OBMEP - 2005/2009). In: Avaliaçáo do impacto da Olimpíada Brasileira de Matemática nas escolas públicas - OBMEP 2010. Brasília: Centro de Gestão e Estudos Estratégicos, 2011. Disponível em: http://monografias.ufma. br/jspui/handle/123456789/2836. Acesso em: 23 mar. 2018. 
MOREIRA, Diana. Recognizing Performance: How Awards Affect Winners' and Peers' Performance in Brazil. 2017. 86 f. Tese (Doutorado), Department Of Economics And Harvard Business School, Harvard University, Estados Unidos, 2017.

MOREIRA, Marco Antonio. Aprendizagem significativa: um conceito subjacente. Aprendizagem Significativa em Revista. Meaningful Learning Review, v. 1, n. 3, p. 2546, 2011. Disponível em: https://lief.if.ufrgs.br/pub/cref/pe_Goulart/Material_de_Apoio/ Referencial\%20Teorico\%20-\%20Artigos/Aprendizagem\%20Significativa.pdf. Acesso em: 25 nov. 2020.

OBMEP. Olimpíada Brasileira de Matemática das Escolas Públicas. Apresentação. 2018. Disponível em: http://www.obmep.org.br/apresentacao.htm. Acesso em: 10 jun. 2018.

SOUSA, Janaildo Soares de et al. A Didática no Ensino de Matemática e sua Contribuição para o Exxito dos Alunos nas Olimpíadas Brasileiras de Matemática - OBMEP: o Caso do Município de Paulista - PB. In: CONEDU, 1., 2014, Campina Grande. Anais [...]. Campina Grande: Realize, 2014. p. 1 - 5. Disponível em: http://www.editorarealize. com.br/revistas/conedu/trabalhos/Modalidade_1datahora_16_08_2014_00_00_44_ idinscrito_5156_9d4930552d079123469f5205e94c6c5d.pdf. Acesso em: 23 mar. 2018. 